\title{
Comparison of Robot-assisted Versus Conventional Laparoscope on Incidence and Risk Factors of Postoperative Delirium for Patients undergoing radical prostatectomy: A single-center Retrospective Analysis
}

GuangJun Hu ( $\square$ jeanhu@163.com )

The Department of Anesthesiology of WuHan third hospital https://orcid.org/0000-0002-9958-1129

Shao Weidong

PLA General Hospital of Southern Theatre Command

Xu Mengda

General Hospital of centeral Theater command of the Chinese PLA

\section{Li Bixi}

General hospital of Central theater command of the Chinese PLA

Li Li

General Hospital of Central Theater command of the Chinese PLA

Xu Bo

General Hospital of southern Theater Command of the Chinese PLA

Research article

Keywords: Robot, Laparoscope, Prostatic Cancer, Delirium

Posted Date: October 29th, 2020

DOI: https://doi.org/10.21203/rs.3.rs-97673/v1

License: (c) (i) This work is licensed under a Creative Commons Attribution 4.0 International License.

Read Full License 


\section{Abstract}

Background: Robot-assisted laparoscopic radical prostatectomy (RALRP) has better effects than conventional laparoscopic radical prostatectomy (LRP). However, there were few research focus on the incidence and risk factors of postoperative delirium for patients with different procedures.

Methods: Eighty-one cases of RLRP patients (group RALRP) and 71 cases of LRP patients (group LRP) under general anesthesia were collected from anesthesia information system from June 2013 to December 2019. Comparison of the time of preparation period before surgery $\left(T_{p}\right)$, time of operation $\left(T_{0}\right)$, time of anesthesia maintenance $\left(T_{a}\right)$, time of anesthesia recovery(time from cessation of intravenous anesthetic to endotracheal extubation, $\mathrm{T}_{\mathrm{r}}$ ), time of endotracheal extubation(time from endotracheal extubation to discharge from post-anesthesia care unit, $T_{e}$ ), dosage of anesthetic (propofol, sufentanil, remifentanil), $\mathrm{P}_{\mathrm{a}} \mathrm{CO} 2$, plasma lactate level and airway pressure at different points (before pneumoperitoneum, post-pneumoperitoneum, after loosening pneumoperitoneum), the incidences of postoperative delirium and utilization of mannitol, IAP, dosage of vasoactive agents(ephedrine, methoxamine and atropine), fluid infusion volume, blood transfusion volume, blood loss, postoperative hospitalization time $\left(T_{h}\right)$ and overall cost.

Results: The incidences of postoperative delirium and utilization of mannitol in group RALRP and LRP were (17.3\% VS 32.4\%, $P=0.03 ; 7.4 \%$ VS 21.1\%, $P=0.014)$, $\mathrm{T}_{\mathrm{r}}$ was (31.52 \pm 9.89 VS 38.65 $\pm 16.32 \mathrm{~min}$; $P=0.01,95 \% \mathrm{Cl} 2.72-11.54)$, IAP was (12.72 $\pm 1.87 \mathrm{VS} 13.37 \pm 1.12 \mathrm{mmHg} ; P=0.01,95 \% \mathrm{Cl} 0.16-1.14), \mathrm{PaCO}_{2}$ at post-pneumoperitoneum and after loosening pneumoperitoneum were (47.89 \pm 10.89 VS $38.65 \pm 16.32$ $\mathrm{mmHg} ; P<0.001,95 \% \mathrm{Cl} 6.47-11.98 ; 40.77 \pm 5.34$ VS 43.57 $\pm 4.54 \mathrm{mmHg} ; P=0.001,95 \% \mathrm{Cl} 1.17-4.37)$, the difference was statistically significant. $T_{p}, T_{0}, T_{a}$ and overall cost of patients in the RLRP group were significantly longer than those in the LRP group $(P<0.02)$. No statistical difference was found in other observation variables. The incidence of postoperative delirium was considered as the dependent variable for binary logistic regression analysis. The result showed the incidence of postoperative delirium increased 1.17 times (95\% C/1.06-1.17), 1.13 times (95\% C/1.03-1.24), and 1.66 times (95\% C/1.02-2.70) for each unit increase in $T_{r}$, post-pneumoperitoneum $\mathrm{PaCO}_{2}$ and IAP.

Conclusion: Compared with group LRP, patients in group RALRP had lower IAP, lower incidence of postoperative delirium and shorter recovery time, but the overall cost was higher. IAP is the main factor affecting the incidence of postoperative delirium.

\section{Background}

Today, robots pervade all aspects of our lives and industries, including, of course, healthcare. Da Vinci assisted laparoscopic system is widely used in radical prostatectomy. Previous Study has shown that compared with open surgery and laparoscopic radical prostatectomy, RALRP has fewer postoperative complications and can be safely used for radical prostatectomy [1]. However, in both RALRP and LRP group, patients need to be in $\mathrm{CO}_{2}$ pneumoperitoneum and placed in Trendelenburg (ST) position to 
provide effective operating space, which has a great influence on the physiology of patients during operation and may affect the incidence of postoperative delirium.

$\mathrm{CO}_{2}$ pneumoperitoneum can promote the inflammatory response during surgery[2], which affects the patient's outcomes. At the same time, this effect varies with the change of intra-abdominal pressure(IAP) [3]. RALRP is similar to LRP, but the difference between the two procedures is that RALRP uses a computer to precisely control the robotic arm, the operation is more accurate and precise, and it can provide a better surgical field of vision and three-dimensional anatomical structure for the surgeon. Therefore, compared with LRP, RALRP requires shorter operation time, lower IAP, and have less impact on patients during operation, and patients recover faster. At present, there is few study in this field. Therefore, we carried out this retrospective study to compare the effects of these two different procedures on operation time, IAP, partial pressure of arterial $\mathrm{CO}_{2}\left(\mathrm{P}_{\mathrm{a}} \mathrm{CO}_{2}\right)$, postoperative outcomes and the incidence of postoperative delirium, and explored the risk factors for postoperative delirium.

\section{Methods}

\section{Patients and groups}

This study is a retrospective study, approved by the General Hospital of Southern Theater command and registered with the China Clinical Trial Center with registration number: ChiCTR1900026479. All patients were not required to sign informed consent. 152 patients undergoing radical prostatectomy performed in the Department of Anesthesiology of General Hospital of Central Theater Command from June 2013 to December 2019 were included. Overall cohort were divided into two group according to the surgical method they received, 81 cases were included in the group RALRPand 71 cases were included in the group LRP,

Inclusion criteria: The anaesthesia documents was recorded in detail, including airway pressure, $\mathrm{P}_{\mathrm{a}} \mathrm{CO} 2$ before pneumoperitoneum, post-pneumoperitoneum, and after loosening pneumoperitoneum. All surgical procedure were performed by the one surgeon. Exclusion criteria: Patients with heart, lung, liver, kidney, respiratory insufficience, disturbance of consciousness, preoperative MMSE less than 27 points, or converted to open surgery during operation.

\section{Measurements}

Demographic variables(age, height, weight, ASA classification, blood pressure, heart rate), the time of preparation for surgery $\left(T_{p}\right)$, time of operation $\left(T_{0}\right)$, time of anesthesia maintenance $\left(T_{a}\right)$, time of anesthesia recovery (time from cessation of intravenous anesthetic to endotracheal extubation, $T_{r}$ ), time of endotracheal extubation(time from endotracheal extubation to discharge from post-anesthesia care unit, $\mathrm{T}_{\mathrm{e}}$ ), dosage of anesthetic (propofol, sufentanil, remifentanil), $\mathrm{P}_{\mathrm{a}} \mathrm{CO} 2$, plasma lactate level and airway pressure at different points (before pneumoperitoneum, post-pneumoperitoneum, after loosening pneumoperitoneum), the incidences of postoperative delirium and utilization of mannitol, IAP, dosage of 
vasoactive agents (ephedrine, methoxamine and atropine), fluid infusion volume, blood transfusion volume, blood loss, time of postoperative hospitalization $\left(\mathrm{T}_{h}\right)$ and overall cost were recorded.

\section{Methods of anesthesia}

In the operating room, all patients were routinely monitored for electrocardiogram (ECG), pulse oxygen saturation $\left(\mathrm{SPO}_{2}\right)$, noninvasive blood pressure and partial pressure of end tidal carbon dioxide $\left(\mathrm{PetCO}_{2}\right)$. Open upper extremity vein for intraoperative infusion. A radial artery cannula was inserted under local anesthesia to monitor blood pressure directly and for arterial blood gas analysis. Nasopharyngeal temperature was monitored by nasal temperature probe. Neuromuscular function was measured using a TOF-Watch acceleromyograph. All patients were induced with etomidate $0.3 \mathrm{mg} / \mathrm{kg}$, sufentanil $0.5 \mu \mathrm{g} / \mathrm{kg}$ and rocuronium $0.9 \mathrm{mg} / \mathrm{kg}$. When TOF ratio was at 0 , intubation is performed. After intubation, ventilation was performed to maintain $\mathrm{P}_{\mathrm{a}} \mathrm{CO}_{2}$ between 35 and $45 \mathrm{mmHg}$. General anesthesia was maintained with propofol, remifentanil and rocuronium. vasoactive drugs (ephedrine $5 \mathrm{mg}$ or methoxy 0.5-1 $\mathrm{mg}$ ) were administered when blood pressure was below basic $20 \%$, and atropine $0.5 \mathrm{mg}$ was administered when heart rate was below 45 beats/min. when the heart rate was higher than 100 beats/minutes, $5 \mathrm{mg}$ of esmolol was administered, and when systolic blood pressure was more than $180 \mathrm{mmHg}$, perdipine 0.2$0.5 \mathrm{mg}$ were administered. When hemoglobin was lower than $70 \mathrm{~g} / \mathrm{L}$, suspended red blood cells was infused. Stop the infusion of propofol 15 minutes before the end of the operation, and reduce the rate of remifentanil infusion. When the operation was over, stop the infusion of remifentanil, give patients dorastron $12.5 \mathrm{mg}$ to prevent vomiting, $40 \mathrm{mg}$ parecoxib sodium to relieve pain. Tracheal catheter was removed when the patient was conscious, spontaneous respiration recovered, TOF value $>90 \%, \mathrm{SPO}_{2}>$ $95 \%$. After endotracheal extubation, the patients were continued to be monitored until they were fully conscious, able to cooperative, and vital signs were stable. If postoperative delirium was found, mannitol was given to dehydrate, or sedated with propofol.

\section{Surgical Procedure}

After general anesthesia, the patients were kept in the prone position, pneumoperitoneum was induced with $\mathrm{CO} 2$ insufflation of $15 \mathrm{mmHg}$. Following the

insertion of trocars, an IAP of $8 \mathrm{mmHg}$ was set from the previous $15 \mathrm{mmHg}$, and a remote control was used to place the patients in a ST position, and IAP was gradually increased until the surgeon was satisfied with the surgical space. The IAP was recorded.

\section{Statistical analysis}

Statistical analysis was performed using SPSS version 25.0. Measurement data are described as mean \pm standard deviation. Demographic variables, $T_{p}, T_{0}, T_{a}, T_{r}, T_{e}$, dosage of anesthetic (propofol, sufentanil, remifentanil), IAP, dosage of vasoactive drugs (ephedrine, methoxamine and atropine), infusion volume, blood transfusion volume, blood loss, $\mathrm{T}_{\mathrm{h}}$ and overall cost were compared using unpaired Student $t$ tests. $\mathrm{P}_{\mathrm{a}} \mathrm{CO} 2$, lactic acid value and airway pressure at different points are repeated measurement data, using repetitive measure analysis of variance. The incidence of postoperative delirium and utilization of 
mannitol, and ASA scores are count data, using chi-square test. Binary logistic regression analysis was performed with postoperative delirium as the dependent variable, $T_{a}, T_{r}, T_{e}, P_{a} C O_{2}$, and IAP as independent variables, to explore the risk factors for postoperative delirium. A $P$ value $<0.05$ was considered statistically significant.

\section{Results}

A total of 152 patients were assessed for eligibility. Demographic variables (age, weight, height, ASA grading, blood pressure and heart rate) of patients in the two groups showed no significant difference ( Table 1).

Table 1

patients characteristics

\begin{tabular}{|llllll|}
\hline & RALRP group & LRP group & statistics & $P$ values & $95 \% \mathrm{Cl}$ \\
\hline sample & 81 & 71 & & & \\
\hline age $(\mathrm{yr})$ & $67.56 \pm 6.82$ & $68.85 \pm 6.37$ & 1.20 & 0.232 & $-0.84-3.81$ \\
\hline weight $(\mathrm{kg})$ & $68.04 \pm 10.13$ & $66.68 \pm 9.06$ & 0.86 & 0.389 & $-4.45-1.74$ \\
\hline height $(\mathrm{cm})$ & $169.78 \pm 5.56$ & $168.97 \pm 4.95$ & 0.94 & 0.350 & $-2.50-0.89$ \\
\hline ASA scores $\mathrm{n}(\%)$ & $28(34.6 \%)$ & $31(43.7 \%)$ & 1.32 & 0.251 & \\
$\square$ & $53(65.4 \%)$ & $40(56.3 \%)$ & & & \\
$\square$ & & & & & \\
\hline systolic pressure(mmHg) & $146.59 \pm 17.03$ & $142.85 \pm 18.93$ & 1.29 & 0.201 & $-9.51-2.02$ \\
\hline diastolic pressure(mmHg) & $81.51 \pm 8.09$ & $79.62 \pm 9.37$ & 1.33 & 0.185 & $-4.68-0.91$ \\
\hline heart rate (beats/min) & $73.46 \pm 10.85$ & $74.62 \pm 11.85$ & 0.63 & 0.529 & $-2.48-4.80$ \\
\hline
\end{tabular}

$T_{p}, T_{o}$ and $T_{a}$ in group RALRP were significantly longer than those in group LRP; $T_{r}$ was significantly shorter than that in group LRP; There was no statistical difference between $T_{e}$ and $T_{h}$ ( Table 2). 
Table 2

Comparison of $T_{p}, T_{0}, T_{a}, T_{r}, T_{e}$, and $T_{h}$ between two groups

\begin{tabular}{|llllll|}
\hline & RALRP group & LRP group & statistics & $P$ value & $95 \%$ Cl \\
\hline sample & 81 & 71 & & & \\
\hline $\mathrm{T}_{\mathrm{p}}$ & $39.10 \pm 6.34$ & $32.15 \pm 6.95$ & 6.44 & $<0.001$ & $4.81-9.07$ \\
\hline $\mathrm{T}_{\mathrm{o}}$ & $235.58 \pm 38.21$ & $216.82 \pm 39.50$ & 2.97 & 0.003 & $6.29-31.23$ \\
\hline $\mathrm{T}_{\mathrm{a}}$ & $280.89 \pm 41.55$ & $264.56 \pm 42.10$ & 2.40 & 0.018 & $2.90-29.75$ \\
\hline $\mathrm{T}_{\mathrm{r}}$ & $31.52 \pm 9.89$ & $38.65 \pm 16.32$ & 3.20 & 0.002 & $2.72-11.54$ \\
\hline $\mathrm{T}_{\mathrm{e}}$ & $30.65 \pm 10.07$ & $32.37 \pm 11.50$ & 0.98 & 0.329 & $-1.74-5.17$ \\
\hline $\mathrm{T}_{\mathrm{h}}$ & $13.11 \pm 6.34$ & $14.52 \pm 8.07$ & 1.21 & 0.230 & $-0.90-3.72$ \\
\hline
\end{tabular}

The dosage of propofol and remifentanil in the group RALRP were higher than those in the group LRP; IAP was lower than that in the group LRP; overall cost was higher than that in group LRP. The incidence of delirium and utilization of mannitol were lower than those in group LRP. There was no significant difference in dosage of sulfentanil, vasoactive agents, fuild infusion volume, blood transfusion volume, and blood loss (Table 3). 
Table 3

Intraoperative and Postoperative Observation Indexes

\begin{tabular}{|c|c|c|c|c|c|}
\hline & RALRP group & LRP group & statistics & $\begin{array}{l}P \\
\text { value }\end{array}$ & $95 \% \mathrm{Cl}$ \\
\hline sample & 81 & 71 & & & \\
\hline propofol(g) & $1.37 \pm 0.27$ & $1.26 \pm 0.30$ & 2.35 & 0.020 & $\begin{array}{l}0.02- \\
0.20\end{array}$ \\
\hline remifentanil(mg) & $5.30 \pm 1.10$ & $4.68 \pm 1.03$ & 3.58 & $<0.001$ & $\begin{array}{l}0.28- \\
0.97\end{array}$ \\
\hline sulfentanyl $(\mu \mathrm{g})$ & $49.51 \pm 10.74$ & $46.69 \pm 10.79$ & 1.61 & 0.110 & $\begin{array}{l}-6.27- \\
0.64\end{array}$ \\
\hline Vasoactive drugs & $1.88 \pm 3.33$ & $2.13 \pm 3.36$ & 0.46 & 0.646 & $-0.82-$ \\
\hline ephedrine(mg) & $0.06 \pm 0.30$ & $0.08 \pm 0.25$ & 0.35 & 0.727 & \\
\hline methoxamine(mg) & $0.21 \pm 0.28$ & $0.28 \pm 0.64$ & 0.91 & 0.364 & 0.10 \\
\hline atropine(mg) & & & & & $\begin{array}{l}-0.08- \\
0.23\end{array}$ \\
\hline $\mathrm{IAP}(\mathrm{mmHg})$ & $12.72 \pm 1.87$ & $13.37 \pm 1.12$ & 2.63 & 0.010 & $\begin{array}{l}0.16- \\
1.14\end{array}$ \\
\hline incidence of delirium(\%) & $14(17.3 \%)$ & $23(32.4 \%)$ & 4.69 & 0.030 & \\
\hline $\begin{array}{l}\text { incidence of utilization of } \\
\text { mannitol(\%) }\end{array}$ & $6(7.4 \%)$ & $15(21.1 \%)$ & 5.98 & 0.014 & \\
\hline $\begin{array}{l}\text { Overall cost(Ten thousand } \\
\text { RMB) }\end{array}$ & $8.29 \pm 5.55$ & $5.18 \pm 1.51$ & 4.57 & $<0.001$ & $\begin{array}{l}1.77- \\
4.45\end{array}$ \\
\hline infusion volume(ml) & $\begin{array}{l}2286.05 \pm \\
581.44\end{array}$ & $\begin{array}{l}2143.61 \pm \\
473.44\end{array}$ & 1.65 & 0.10 & $\begin{array}{l}-314.91- \\
28.02\end{array}$ \\
\hline blood transfusion volum(ml) & $\begin{array}{l}51.85 \pm \\
230.37\end{array}$ & $25.35 \pm 87.37$ & 0.91 & 0.362 & $\begin{array}{l}-83.82- \\
30.82\end{array}$ \\
\hline blood loss(ml) & $\begin{array}{l}183.33 \pm \\
109.26\end{array}$ & $\begin{array}{l}203.5 \pm \\
123.15\end{array}$ & 1.07 & 0.286 & $\begin{array}{l}-17.06- \\
57.43\end{array}$ \\
\hline
\end{tabular}

There was statistically significant difference of $\mathrm{P}_{\mathrm{a}} \mathrm{CO}_{2}$ between groups; $\mathrm{P}_{\mathrm{a}} \mathrm{CO}_{2}$ at time points of postpneumoperitoneum and after loosening pneumoperitoneum in group RALRP was lower than that in group LRP (Fig. 1). There was no statistically difference of plasma lactate concentration between two groups, but there was statistically significant difference of plasma lactate concentration within groups and the change of that in group RALRP was smaller than that in group LRP(Fig. 2). There was no statistically difference of airway pressure between groups, but there was statistically significant difference of airway pressure within groups and the change of airway pressure in group RALRP was smaller than that in group LRP(Fig. 3). 
Binary logistic regression analysis was performed with postoperative delirium as the dependent variable, $\mathrm{T}_{\mathrm{a}}, \mathrm{T}_{\mathrm{r}}, \mathrm{T}_{\mathrm{e}}, \mathrm{P}_{\mathrm{a}} \mathrm{CO}_{2}$ (Pp, Alp), and IAP as independent variables. Using the Enter method, $P<0.05$ was entered into the equation and $P>0.1$ was removed from the equation. The results showed that $T_{r}, P C O_{2}(P p)$ and IAP were entered into the equation and the formula was obtained as follows: Logit $(P)=-18.55+0.11 \times$ $\mathrm{T}_{\mathrm{r}}+0.12 \times \mathrm{PaCO} 2(\mathrm{Pp})+0.50 \times$ IAP. The result showed the incidence of postoperative delirium increased 1.17 times (95\% $C / 1.06-1.17), 1.13$ times (95\% $C / 1.03-1.24)$, and 1.66 times $(95 \% C / 1.02-2.70)$ for each unit increase in $\mathrm{T}_{r}, \mathrm{PaCO}_{2}(\mathrm{Pp})$ and IAP. With the prediction probability 0.5 as the cut-off point, the sensitivity of judging the incidence of postoperative delirium was $67.6 \%$, the specificity was $95.7 \%$, and the total correct rate was $88.8 \%$ (Table 4,5 ).

Table 4

The results of binary logistic regression

\begin{tabular}{|lllllll|}
\hline & $B$ & SE & Wald & $P$ & OR & $95 \%$ Cl \\
\hline $\mathrm{T}_{\mathrm{r}}$ & 0.11 & 0.03 & 19.90 & $<0.001$ & 1.12 & $1.06-1.17$ \\
\hline $\mathrm{PaCO}_{2}(\mathrm{Pp})$ & 0.12 & 0.05 & 6.49 & 0.011 & 1.13 & $1.03-1.24$ \\
\hline $\mathrm{IAP}$ & 0.50 & 0.25 & 4.07 & 0.044 & 1.66 & $1.02-2.70$ \\
\hline
\end{tabular}

Table 5

Model classification table with the prediction probability 0.5 as the cutoff point

\begin{tabular}{|lllll|}
\hline & \multicolumn{4}{c|}{ delirium } \\
\hline Observed & & NO & YES & Correct percentage(\%) \\
\hline delirium & NO & 110 & 5 & 95.7 \\
\cline { 2 - 5 } & YES & 12 & 25 & 67.6 \\
\hline Overall Percentage(\%) & & & & 88.8 \\
\hline
\end{tabular}

\section{Discussion}

tumor of prostate is the one of most common disease in elderly patients over 60 years[5]. Open radical prostatectomy has been the reference standard for treatment of prostate cancer. Recently, surgical approaches to prostate cancer treatment have been replaced by minimally invasive techniques such as LRP and RALP[6]. Previous study has shown RALRP improves clinical effect comparing with open radical prostatectomy and LRP, the time of operation of RALRP was longer than that of LRP from 2000 to 2005, but the time of operation of RALRP was shorter than that of LRP from 2014 to 2016[1]. Meanwhile, our study found that the $T_{p}, T_{0}, T_{a}$ of RALRP was significantly longer than that of LRP, which may be related to the surgical skill of the surgeon. Because our hospital started using Da Vinci surgical operating system 
for RALRP only in September 2017, and surgeon have more than ten years of experience with hundreds of LRP operations, that may help to explained whythe dosage of propofol and remifentanil were higher in the group RALRP than that in the group LRP.

A study has shown that the incidence of postoperative delirium in robotic assisted esophageal surgery was about $30 \%$, significantly lower than that in open surgery [8]. Our study found that the incidence of postoperative delirium in the group RALRP was $17.3 \%$, which may be due to the need for single lung ventilation during esophageal surgery, which could increase the incidence of postoperative delirium. Meanwhile, our study showed that the incidence of postoperative delirium in group LRP was $32.4 \%$ significantly higher than that in group RALRP(17.3\%). $T_{r}$ in group RALRP and LRP was $31.52 \pm 9.89$ and $38.65 \pm 16.32 \mathrm{~min}$, respectively, which indicated that RALRP could be significantly reduced the incidence of postoperative delirium and recovery time.

Similar to LRP, RALRP requires insufflation of the abdomen with carbon dioxide (CO2) pneumoperitoneum and the steep Trendelenburg (ST) position to create an optimal surgical space, which are associated with a number of problems, including hypercapnia, brain edema and other complications. These complications affected the postoperative recovery and increase the incidence of postoperative delirium[9]. Rapid infusion and absorption of $\mathrm{CO}_{2}$ and high pressure pneumoperitoneum increased intraabdominal pressure, leaded to internal and external organs ischemia, increased postoperative pain, and resulted many physiological disorders [10]. Meanwhile, $\mathrm{CO}_{2}$ harmed organs by promoted oxidative stress and inflammatory response[2]. Studies have shown that the incidence of postoperative delirium and cognitive dysfunction may be related to the inflammatory response of the central nervous system $[15,16]$. Reducing IAP and $\mathrm{P}_{\mathrm{a}} \mathrm{CO}_{2}$ could reverse this adverse effect[3]. Trendelenburg position could aggravate the mentioned adverse effect and change the intracranial hemodynamics subsequently increased intracranial pressure. Our study has found that post-pneumoperitoneum PaCO2 and IAP in group RALRP were significantly lower than those in group LRP, which may be the explanation for the lower incidence of postoperative delirium and the short recovery time in group RALRP. Zhou[9] et al. showed that A small dose of mannitol can effectively improve cerebral oxygen metabolism and protect cognitive function after the operation. author work in the same department as Zhou's. When patients had severe delirium after surgery, we first gave them a small dose of mannitol. We also sedated patients with propofol and gradually remove the endotracheal extubationendotracheal tube after the delirium remission. $T_{r}$ in the group RALRP was significantly lower than that in the group LRP, which was associated with the low incidence of postoperative delirium in the group RALRP. However, there was no difference of $T_{e}$ between RALRP and LRP, mainly because all patients were removed trachea tube with completely awake and without delirium. Meanwhile, the patients left the post-anesthesia care unit with the same standards, the vital signs patients after endotracheal extubation were similar, and the dosage of vasoactive drugs in the two groups were similar.

There are many factors affecting delirium after surgery, and pain is one of the factors [18]. Studies have shown that low IAP can reduce pain in patients during laparoscopic surgery [19-21]. Our study found 
that the IAP of patients in the group RALRP was significantly lower than that in the group LRP(12.72 \pm 1.87 VS $13.37 \pm 1.12 \mathrm{mmHg}, P<0.05)$, so the patients in group RALRP suffered less postoperative pain, resulting lower incidence of operative delirium. Meanwhile, through binary logistic regression analysis, our study found that each unit of IAP increased the postoperative delirium rate by 1.66 times.

RALRP is similar to LRP, surgeon need to use $\mathrm{CO} 2$ to provide effective operating space. But the difference between the two procedures is that the computerized electromechanical controls give the surgeon much more precision and stability for the dissection of critical structures, and the console has tridimensional vision, which provides depth of field and helps immensely with regard to orientation and surgical precision[4]. Therefore, compared with LRP, RALRP needs a lower IAP to satisfy the surgeon's requirements for surgical space, which is the reason for why IAP in the group RALRP was significantly lower than in the group LRP. Our study did not find differences in postoperative hospital stay and blood loss between the two groups, which was different from other studies $[1,22]$. The overall cost of patients in the RALRP group is higher than that in the LRP group, which may hinder the development of RALRP in China.

\section{Conclusion}

Our retrospective study showed that IAP was the most important factor affecting the incidence of postoperative delirium, and controlling IAP may help reduce the incidence of postoperative delirium. However, the underlying mechanism was not clear and needed to be discussed in future studies. In summary, compared with group LRP, patients in group RALRP had lower IAP, lower incidence of postoperative delirium and shorter recovery time, but the overall cost was higher.

\section{Abbreviations}

RALRP: Robot-assisted Laparoscopic Radical Prostatectomy

LRP: Laparoscopic Radical Prostatectomy

$\mathrm{P}_{\mathrm{a}} \mathrm{CO}_{2}:$ Partial Pressure of Arterial $\mathrm{CO}_{2}$

IAP: Intra-abdominal Pressure

MMSE: Mini-mental State Exam

ASA: American Society of Anesthesiology

TOF: Train of Four Stimulation

\section{Declarations}

\section{- Ethics approval and consent to participate}


This study was approved by the General Hospital of Southern Theater command and written informed consent was obtained before study from all patients.

\section{- Consent for publication}

Not applicable

\section{- Availability of data and material}

The date used and/or analyzed during the current study are available from the corresponding author on reasonable request.

\section{-Competing interests}

The authors declare that they have no competing interests.

\section{-Funding}

This paper was supported by fund of National Natural Science Foundation of China (NO. 61773130) and Guangzhou science and technology program (NO. 201904010389)

\section{-Authors' contributions}

HGJ and XB contributions to study conception and design, data analysis and interpretation, and preparation of the manuscript. SWD, XMD, LBX and LL participated in data collection and analysis. All authors read and approved the final manuscript.

\section{-Acknowledgements}

Not applicable

\section{References}

1. Basiri A, de la Rosette JJ, Tabatabaei S, et al. Comparison of retropubic, laparoscopic and robotic radical prostatectomy: who is the winner?[J]. World J Urol. 2018;36(4):609-21.

2. Cho JS, Oh YJ, Kim OS, et al. The effects of arginase inhibitor on lung oxidative stress and inflammation caused by pneumoperitoneum in rats[J]. BMC Anesthesiol. 2015;15:129. 
3. Niu X, Song X, Su A, et al. Low-pressure capnoperitoneum reduces stress responses during pediatric laparoscopic high ligation of indirect inguinal hernia sac: A randomized controlled study[J]. Medicine. 2017;96(14):e6563.

4. Baltayian S. A brief review: anesthesia for robotic prostatectomy[J]. J Robot Surg, 2008,2(2):59.

5. Siegel RL, Miller KD, Jemal A. Cancer Statistics, 2017[J]. CA Cancer J Clin. 2017;67(1):7-30.

6. Michael L, Inna S, Ramin M, et al. Complications, urinary continence, and oncologic outcome of 1000 laparoscopic transperitoneal radical prostatectomies-experience at the Charité Hospital Berlin, Campus Mitte.[J]. European urology, 2006,50(6).

7. Laurent B. Radical prostatectomy: open? Laparoscopic? Robotic?[J]. European urology, 2006,49(4).

8. Jeong DM, Kim JA, Ahn HJ, et al. Decreased Incidence of Postoperative Delirium in Robot-assisted Thoracoscopic Esophagectomy Compared With Open Transthoracic Esophagectomy[J]. Surg Laparosc Endosc Percutan Tech. 2016;26(6):516-22.

9. Zhou $X$, Wu M, Wang $Y$, et al. Mannitol improves cerebral oxygen content and postoperative recovery after prolonged retroperitoneal laparoscopy[J]. Surg Endosc. 2013;27(4):1166-71.

10. Kim MH, Lee KY, Lee K, et al. Maintaining Optimal Surgical Conditions With Low Insufflation Pressures is Possible With Deep Neuromuscular Blockade During Laparoscopic Colorectal Surgery[J]. Medicine. 2016;95(9):e2920.

11. H A R NLS, R W J. Neuroinflammation and cognitive function in aged mice following minor surgery. [J]. Experimental gerontology, 2008,43(9).

12. Niccolò $T$, Claudia $M$, Daqing $M$, et al. Tumor necrosis factor-alpha triggers a cytokine cascade yielding postoperative cognitive decline.[J]. Proceedings of the National Academy of Sciences of the United States of America, 2010,107(47).

13. Mario C, Antonio Rei F, Niccolò T, et al. Role of interleukin-1beta in postoperative cognitive dysfunction.[J]. Annals of neurology, 2010,68(3).

14. Hirsch J, Vacas S, Terrando N, et al. Perioperative cerebrospinal fluid and plasma inflammatory markers after orthopedic surgery[J]. J Neuroinflamm. 2016;13(1):211.

15. Li Y, Pan K, Chen L, et al. Deferoxamine regulates neuroinflammation and iron homeostasis in a mouse model of postoperative cognitive dysfunction[J]. J Neuroinflamm. 2016;13(1):268.

16. Zhang $\mathrm{X}$, Dong $\mathrm{H}$, Li N, et al. Activated brain mast cells contribute to postoperative cognitive dysfunction by evoking microglia activation and neuronal apoptosis[J]. J Neuroinflamm. 2016;13(1):127.

17. Chen K, Wang L, Wang Q, et al. Effects of pneumoperitoneum and steep Trendelenburg position on cerebral hemodynamics during robotic-assisted laparoscopic radical prostatectomy[J]. Medicine. 2019;98(21):e15794.

18. Nishizawa Y, Hata T, Takemasa I, et al. Clinical benefits of single-incision laparoscopic surgery for postoperative delirium in elderly colon cancer patients[J]. Surg Endosc. 2018;32(3):1434-40. 
19. Matsuzaki S, Vernis L, Bonnin M, et al. Effects of low intraperitoneal pressure and a warmed, humidified carbon dioxide gas in laparoscopic surgery: a randomized clinical trial[J]. Scientific Reports, 2017,7(1).

20. Kim MH, Lee KY, Lee K, et al. Maintaining Optimal Surgical Conditions With Low Insufflation Pressures is Possible With Deep Neuromuscular Blockade During Laparoscopic Colorectal Surgery[J]. Medicine. 2016;95(9):e2920.

21. Madsen MV, Istre 0 , Staehr-Rye AK, et al. Postoperative shoulder pain after laparoscopic hysterectomy with deep neuromuscular blockade and low-pressure pneumoperitoneum[J]. Eur $\mathrm{J}$ Anaesthesiol. 2016;33(5):341-7.

22. Brandao LF, Autorino R, Zargar H, et al. Robot-assisted Laparoscopic Adrenalectomy: Step-by-Step Technique and Comparative Outcomes[J]. Eur Urol. 2014;66(5):898-905.

\section{Figures}

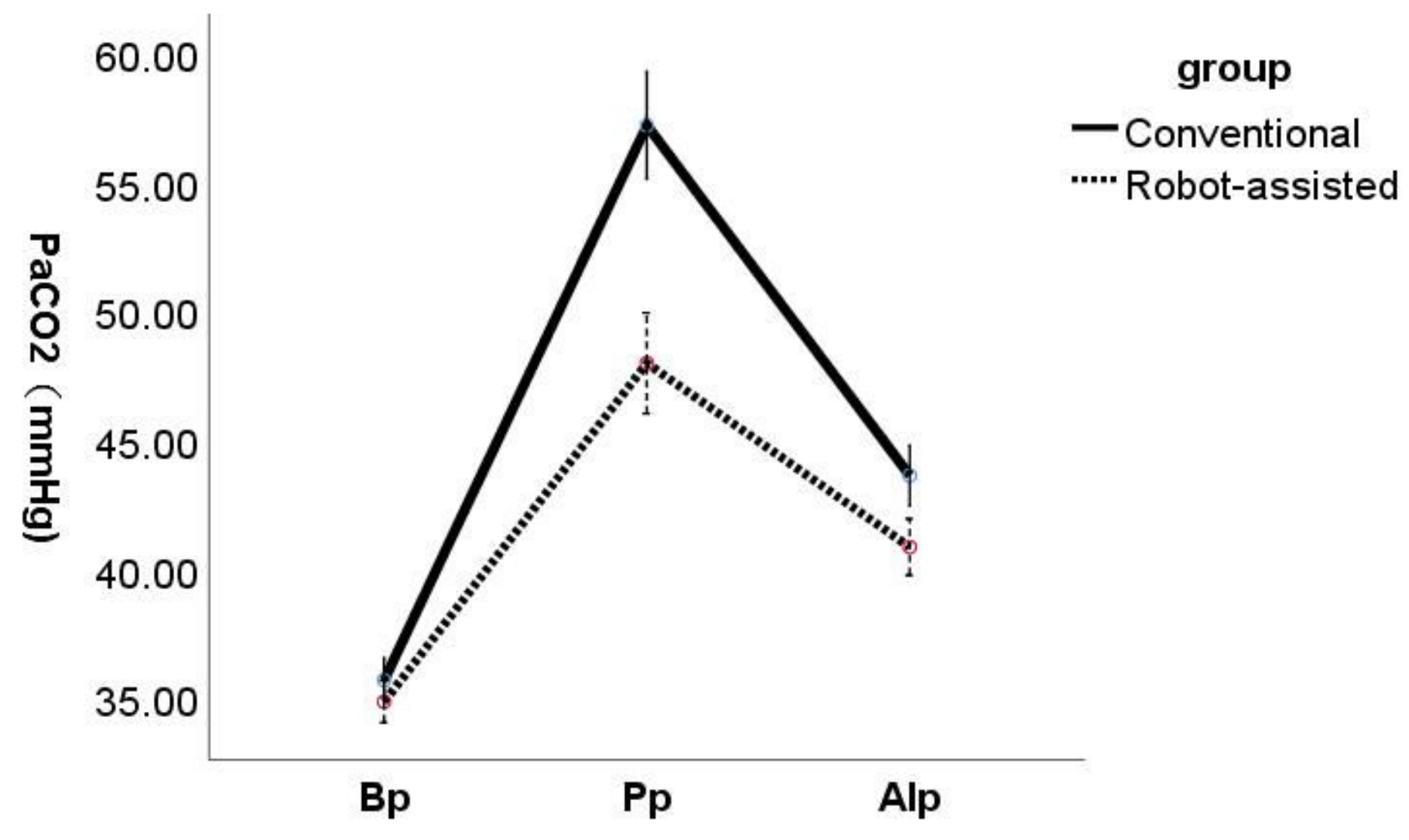

Time

Figure 1

$\mathrm{PaCO} 2$ at different time points in the two groups $\mathrm{Bp}=$ before pneumoperitoneum, $\mathrm{PP}=$ post pneumoperitoneum, Alp = after loosening pneumoperitoneum 


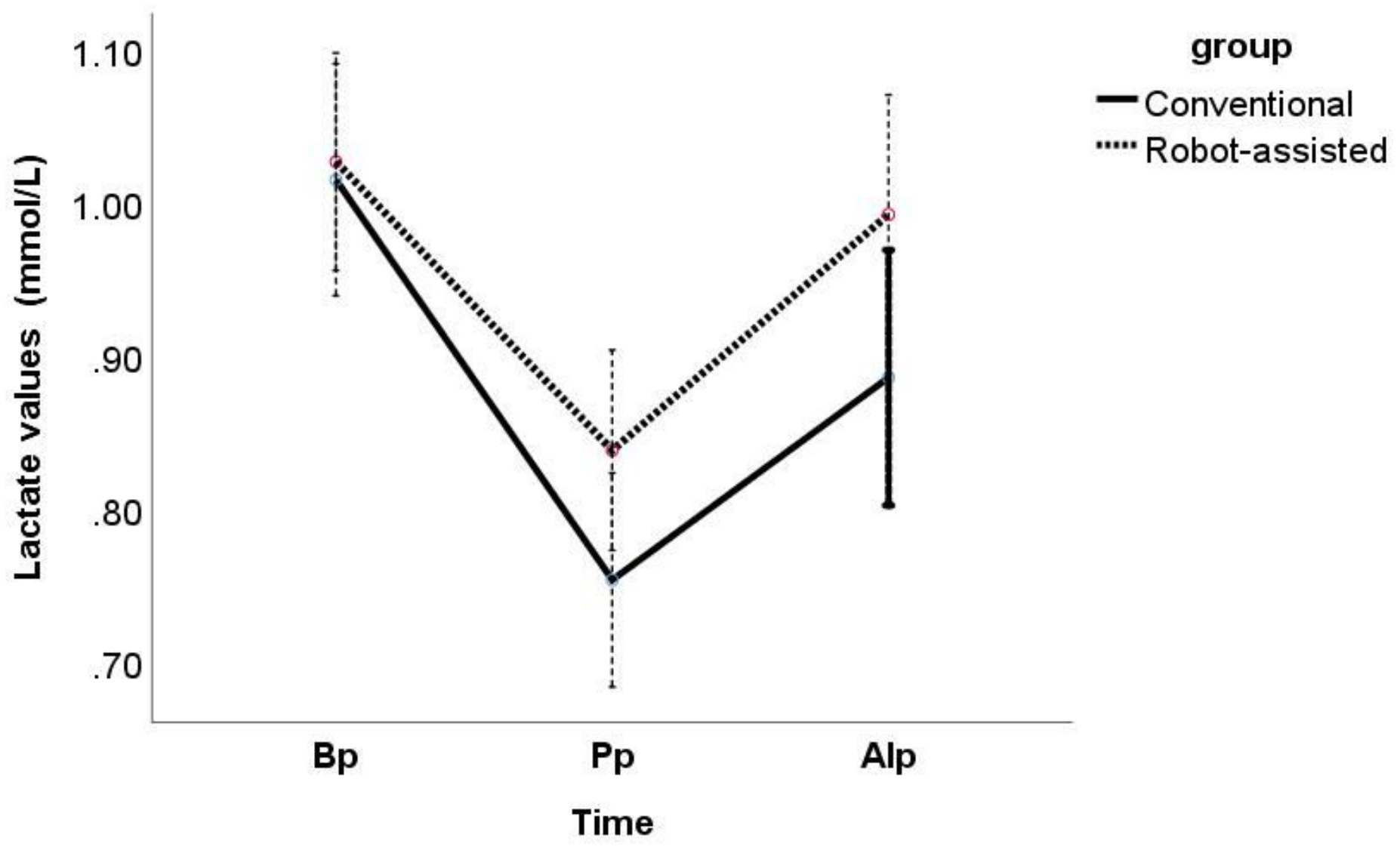

Figure 2

plasma lactate concentration at different time points in the two groups 


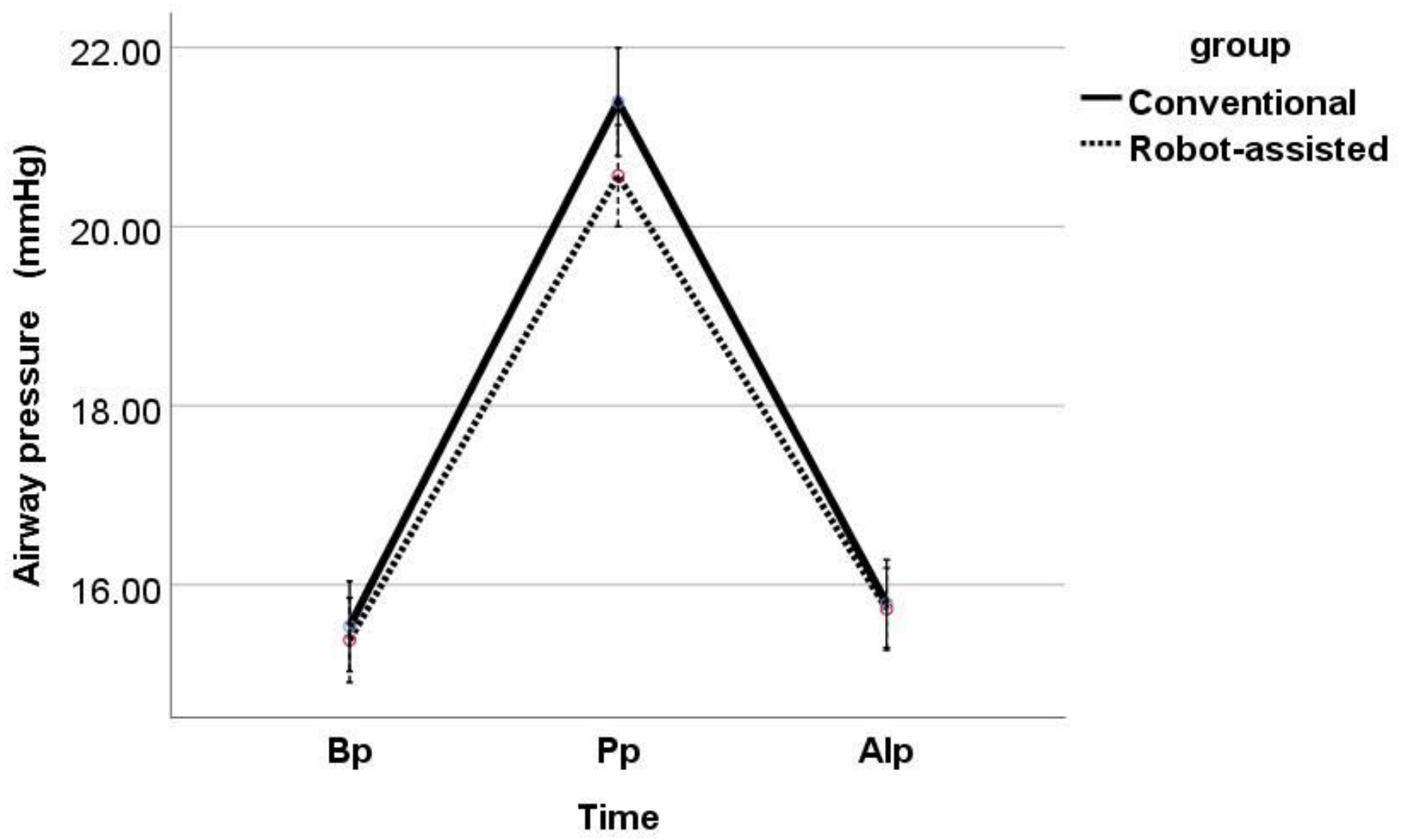

Figure 3

Airway pressure at different time points in the two groups 